\title{
11
}

\section{DISPUTING SECURITY AND RISK}

\section{The convoluted politics of uncertainty}

\author{
Helena Farrand Carrapico, Narzanin Massoumi, \\ William McGowan and Gabe Mythen
}

\section{Introduction}

Uncertainty has become a prevalent, but arguably oblique, signifier in recent years, with economic crisis, climate emergency and the threat of terrorism contributing to a tangible - yet simultaneously free-floating - sense of incertitude. To speak in the abstract about 'uncertainty' in such politically charged times is thus problematic. In this chapter, we argue for a grounded, context-specific account of uncertainty, drawing on vignettes that enable us to think practically about the nature of uncertainty and to explore the ways in which incertitude connects to other political, cultural and economic processes and forces. We will grapple with the impacts of discourses of uncertainty in three areas: cyber security, counter-terrorism and coping mechanisms in the aftermath of structural violence. It is our intention not only to engage with, but moreover to problematise, dominant understandings of 'risk' and 'security' in each of these domains. Elucidating salient problems and issues, our intention is to be forthright in challenging settled assumptions around the nature of uncertainty, and also its pervasiveness. Counselling against conceptual overreach, we contend that the explanatory power of more traditional sociological frames of analysis - such as power, ideology and social control - should not be marginalised by the omnipresence of debates about uncertainty.

In order to tease out the political dimensions of uncertainty, as they intersect with issues of risk and security, we turn first to the case of cyber security, with a specific emphasis on the implications of the UK's exit from the European Union for the regulation of future UK-EU security relations. From here, we explore further the mobilisation of uncertainty as a lever for politics and policy, focusing on the deleterious effects of pre-emptive anti-terrorism and counter-radicalisation measures in the UK. Finally, we reflect on survivors' accounts of managing uncertainty in the aftermath of surviving structural violence. 
In order to organise our discussion we direct attention to two key themes that cut across and cement together research undertaken by the chapter contributors in these three areas. These relate, in turn, to governance, power and accountability, and the ideological mobilisation of uncertainty. In prioritising these themes we highlight some of the ways in which states engage with situations of 'not-knowing' and illuminate the ways in which political elites are able to harness the politics of uncertainty not only as a mode of governance, but also as a means of bolstering social control. These topics constitute central problems for modern nation states, with efforts to counter them commanding a sizeable amount of political energy, large tranches of public expenditure and considerable material resources for the police, criminal justice system and intelligence services. The UK government's National Risk Register - which assesses large-scale threats - considers the threat of cyber and terrorist attacks as 'high', both in terms of likelihood of occurrence and severity of impact. In relation to cyber security, the frequency and the scale of attacks continues to proliferate. Given enhanced connectivity between digital systems, there is a clear possibility of attacks of greater magnitude, with public and private sector organisations considered to be 'at risk' (see National Risk Register of Civil Emergencies 2017: 63). There is, of course, discernible overlap between cyber security and national security - especially given instances of attacks designed to destabilise military and intelligence - with both organised groups and lone individuals who are committed to violence seeking to launch cyber-attacks that destabilise state security and disrupt processes of capital accumulation. Further, widespread concerns have been expressed in political discourse and policy about the emergence of new types of terrorist violence:

Many of those networks and individuals who are judged to pose a terrorist threat share an ambition to cause large numbers of casualties without warning. Some have aspirations to use non-conventional weapons such as chemical, biological, radiological and nuclear substances. Others aspire to attack our national infrastructure using both traditional methods and more novel methods such as electronic attack (National Risk Register of Civil Emergencies 2017: 26).

Given pronounced institutional anxieties, it is unsurprising that the current UK threat level for international terrorism - set by the Joint Terrorism Analysis Centre is classified as 'substantial', meaning that an attack is 'highly likely'. While framing matters of security in this way may incline us to an understanding of risk and uncertainty that is slanted towards institutional regulation determined by expert systems, such a proclivity may encourage a somewhat partial view. The state has a formal duty to protect citizens from harm through implementing protective policies and practices, but risk and uncertainty are also lived and experienced by individuals in the course of everyday life. As we shall argue, risks and uncertainties are not naturally occurring, flat and horizontal phenomena; rather, they emerge in specific locales under particular political, economic and cultural conditions (McGowan 2018). This is significant, as it infers that uncertainties are both produced by and 
affect different people to different degrees and in different ways. As Ian Scoones (2019: 4) reasons, extant forms of stratification - such as gender, class, ethnicity and age - are salient factors in understanding the uneven impacts of uncertainty.

\section{Governing cyber security: competing narratives}

The first section of the chapter, led by Helena Farrand Carrapico, explores the governance of Brexit uncertainty in the context of cyber security policy. Cyber security is considered to be an intensely uncertain field, with ever-increasing levels of attacks on information systems and their users being reported (EC 2018). Not only is cyber insecurity understood as affecting the daily running of societal infrastructures and citizens' lives, it is also construed as having the potential to undermine fundamental rights, democracy and the rule of law: 'malicious cyber activities not only threaten our economies and the drive to the Digital Single Market, but also the very functioning of our democracies, our freedoms and our values' (EC 2017: 2). Nowadays, 'cyber security is about defending our way of life' (UK National Cyber Security Centre 2019: 1). This potential for harm has been framed as an existential form of uncertainty that is often associated with societal dependence on fast-evolving technology, mass production of personal digital data, anonymity of attackers and a lack of technical knowledge and resilience among the public. It is also portrayed as a pervasive type of uncertainty, with cyber-attacks presented as affecting all levels of society, from large companies to state infrastructure and the general public (EC and HREU 2013).

Given the discursive context, it is easy to understand why the current threat level has been flagged as a major concern at international, European and national levels (UK National Cyber Security Centre 2019), and also why cyber security has, in recent years, jumped to the forefront of many political and business agendas (Carrapico and Barrinha 2017). It is equally unsurprising that EU citizens' perceptions of cyber security and their attitudes towards internet security have changed considerably, with a recent poll indicating that 79 per cent of those surveyed believed that the risk of becoming a victim of cyber-crime is increasing (EC 2019). The framing of cyber security as a deeply uncertain field has enabled a wide range of actors, including both state and private actors, to propose and apply a range of policies directed towards addressing cyberspace-calculated risks. This process has been particularly evident within the EU, with uncertainty being used as one of the key justifications for the introduction and development of a joint macro-level cyber security policy and strategy (EC and HREU 2013). Given the borderless nature of cyber-attacks, closer cooperation between EU member states has been presented as the logical answer to the uncertainties of cyberspace.

The governance of Brexit, following the 2016 EU membership referendum, has introduced new forms of complexity in an already uncertain field, with business and practitioner concerns being vocally articulated (Harcup 2019). The main difference between 'new' forms of uncertainty and cyber security emanates from the idea that Brexit constitutes a step into the complete unknown. Whereas cyber security is often couched in terms of risks, which are considered to be calculable 
and insurable, the Brexit process brings considerable uncertainty to the sector. The rupture in the relationship between the EU and the UK triggered by Brexit means that the full consequences of the process on both the sector and the wider economy are unpredictable and largely unknown (see Anan 2019). The lack of historical, political and legal reference points reinforces uncertainties and serves to render the task of imagining post-Brexit futures necessarily speculative.

In practice, the governance of Brexit has resulted, above all, in a crisis of knowledge, which in turn has led to a crisis in decision-making. More specifically, incertitude in this case has both political and operational dimensions. Operationally, Brexit is likely to disrupt seriously, if not to interrupt entirely, the flow of cyber security-related information regularly exchanged by national authorities responsible for countering online threats (Stevens and O'Brien 2019). Regarding the explicitly political dimensions, Brexit has the potential to damage the UK's reputation as a key policy entrepreneur in cyber security. As an EU outlier post-Brexit, the UK is likely to have limited or no access to EU institutions and agencies. In addition, even if the UK is able to secure a degree of access, it will not be allowed to take part in decision-making, including involvement in voting processes. Clearly, Brexit has the potential to reduce the levels of trust that the UK-EU relationship has previously benefited from and which has enabled strategic and operational cooperation to flow in the field of cyber security (Carrapico et al. 2019).

The practitioner-led narratives on uncertainty recounted above have, however, not circulated without contest or challenge. As part of the UK government's process of negotiating an exit from the EU, considerable political efforts have been put into creating a counter-narrative that emphasises that the UK and the EU will continue to exchange cyber security-related intelligence and that the UK will still be able to shape EU standards and incident responses, as other formal and informal channels can be used to cooperate in cyber security beyond the EU, including the Five Eyes framework and NATO: 'pretty much everything we do now to help European partners, and what you do to help us, on cyber security can, should, and I am confident, will, continue beyond Brexit' (Martin, cited in Ashford 2019). Whatever the upshot of Brexit in the domain of cyber security, such narratives and counternarratives demonstrate competing ways in which uncertainty is not only understood but, moreover, is being ideationally massaged to suit particular political and economic ends. The fact that this is a nascent - but increasingly vital - policy field allows us to observe some of the ways in which discourses of certainty and uncertainty are created and disseminated. In addition, a critical analysis of the cyber risks triggered by Brexit enables us to envision how these discourses are co-produced and mutually responsive, as each jostles to become the dominant and commonly accepted security narrative.

\section{Counter-terrorism: the strategic exploitation of uncertainties}

In this section, Narzanin Massoumi discusses the strategic exploitation of uncertainties through the UK government's counter-radicalisation strategy, Prevent, 
focusing primarily on the relationship between government and two sets of nongovernmental actors that played a significant role in delivering and developing anti-terrorism initiatives. The first set of actors are state-supported civil society organisations that rely on government support through funding, institutional access and other resources. In the first iteration of Prevent, such organisations were overtly linked to the government and included agencies like the Quilliam Foundation (now Quilliam). Following a shift in strategy from 2011 onwards, the government adopted a set of discreet relations with a new set of state-supported organisations in order to compensate for previous failures in gaining legitimacy. The second key group of actors are neo-conservative think tanks - such as the Henry Jackson Society - which have successfully lobbied for changes in government policy in this area. As we shall see, these non-governmental organisations have played a significant role in supporting and enacting Prevent. The publicly autonomous nature of these organisations means that they are not subjected to official forms of scrutiny, raising to the fore issues of power and accountability.

The Prevent strategy was devised in 2003 under the presiding Labour government, but was formally launched in 2007 following the ' $7 / 7$ ' London bombings. The strategy is underpinned by the presumption that the roots of politically and religiously motivated violence lie in the propagation of 'extremist' ideas - in other words, that a continuum operates that stretches from initial adoption of radical ideas through to committing acts of terrorism. Prevent is based on pre-emptive principles and serves as a 'pre-crime' measure, designed to promote early intervention to avert later occurrence of harm. While the Prevent strategy seeks to model future threats by identifying indicators of vulnerability to extremist ideology and 'drivers' of violent behaviour, its design, implementation and impacts have been widely criticised since its inception (Mythen et al. 2017; Kundnani 2009; 2015; Dodd 2009). In the first iteration of the Prevent strategy, the stated objective was to 'work with Muslim communities to isolate, prevent and defeat violent extremism' (DCLG 2007). As a result, there was a concerted drive to fund Muslim civil society organisations - via the Department for Communities and Local Government that would work directly on tackling 'violent extremism'. This saw the largest ever injection of funding into Muslim civil society in the UK, with \&60 million being directed to 'third sector' agencies to counter extremism (O'Toole et al. 2013). At the same time, Prevent funding was controversially allocated to local authorities on the basis of the proportion of Muslims living in the locale (Mythen et al. 2017; Kundnani 2009). While 'capacity building' initiatives were focused on empowering Muslim minority communities, the government's drive to recruit partners to assist in the counter-terrorism agenda proved difficult. The Prevent programme faced widespread criticism from human rights groups, academics and activists for being selective in its engagement with Muslim groups and excluding those critical of UK foreign policy or domestic counter-terrorism measures. The strategy was also criticised for its heavy policing of civil society organisations and its surveillant ambitions in gathering data for intelligence purposes (Kundnani 2015; Dodd 2009). 
Following a review conducted by the then independent reviewer of terrorism legislation, David Anderson QC, the Conservative/Liberal Democrat coalition government issued a second iteration of Prevent in 2011 (HM Government 2011). The revised strategy included significant modifications. First, following lobbying by neoconservative groups, there was a move from exclusively tackling 'violent extremism' to also combating 'non-violent extremism'. Second, the revised strategy purported to address a wider variety of forms of extremism, including that emanating from the far right; although, as we shall see, the policy has always disproportionately targeted 'Islamist extremism'. Third, overall responsibility for Prevent was centralised in the Home Office, with community cohesion activities remaining with the Department for Communities and Local Government. Fourth, and not expressed in the formal strategy, a shift towards working covertly with Muslim civil society groups occurred. Following the failure of government counter-radicalisation measures to gain legitimacy among Muslim civil society, in 2012 the UK government adopted a policy of covertly funding Muslim civil society organisations that would politically align with state priorities as the statement below by the former British prime minister, Theresa May, shows:

Often it is more effective to be working through groups that are recognized as having a voice ... rather than it being seen to be government trying to give a message. Indeed, it's always better to be using those people to whom people look naturally to hear the message, rather than simply doing it as RICU itself (Intelligence and Security Committee 2012).

The Research Information and Communications Unit, based in the Home Office and referred to by Theresa May above, led these covert elements of Prevent, employing the services of a public relations company called Breakthrough Media to create social media campaigns in order to promote pro-government messaging (Massoumi and Miller 2019; Massoumi et al. 2019). RICU covertly supported, via Breakthrough Media, campaigns purporting to emanate from grassroots Muslim civil society groups challenging 'extremism' in local communities. One such campaign was fronted by Families Against Stress and Terror, which describes itself as an independent organisation that offers 'support to vulnerable families and individuals'.Yet, in a leaked internal Office for Security and Counter-Terrorism document marked 'not for public disclosure', FAST's 'Families matter' campaign is described as a 'RICU product' that has been 'led and developed' by FAST but 'supported by ... PR and online activity' (Miller and Massoumi 2016). FAST is but one of many ostensibly grassroots organisations that play a role in counter-radicalisation initiatives, and that have been afforded discreet Home Office support (Hooper 2017; Cobain et al. 2016). The covert nature of these initiatives creates uncertainty throughout Muslim civil society, as people are unaware which initiatives are linked to government and which are not.

In 2015, the Prevent programme was placed on a statutory footing, following the Counter-Terrorism and Security Act 2015. This required public institutions to 
pay 'due regard' to 'prevent people being drawn into terrorism'. Although Prevent in the public sector is supposed to be guided by the Prevent Duty Guidance (HM Government 2015a), in practice there exists uncertainty about if, how and when to implement it. This trajectory of the Prevent programme has been heavily influenced by neo-conservative think tanks with strongly defined neo-conservative viewpoints on issues such as religion, immigration, integration and terrorism. In Britain, neo-conservative organisations such as the Henry Jackson Society and Policy Exchange routinely lobby government and promote authoritarian, exclusionist polices. Such think tanks have published a series of reports purporting to show 'evidence' of extremism among British Muslims - calling on government to sever links with particular individuals and groups and urging intensified surveillance of Muslims. In addition to being morally dubious and socially retrogressive, the evidence presented for such calls is highly questionable. To give but one example, a report by the Policy Exchange was withdrawn by the think tank after the BBC established that receipts claiming to establish that 'extremist' literature was being sold in British Mosques had been forged (see Mills et al. 2011). There are numerous instances in which the 'research' of right-wing think-thanks alleging extremist activities by British Muslims has been challenged for being either inaccurate or highly exaggerated. The specific examples that have come to light signal broader concerns about the integrity of their research practices (Miller et al. 2017). Mediating and endorsing Islamophobic discourses in the public sphere and attempting to influence security policy are, lamentably, embedded activities for many neo-conservative think tanks. For example, the Centre for Social Cohesion later incorporated into the Henry Jackson Society - and Policy Exchange were at the forefront of pushing for the revision of the Prevent strategy to include 'nonviolent' extremism. Following these mobilisation efforts, the Prevent policy was expanded to include 'non-violent extremism', with the Centre for Social Cohesion being cited no fewer than six times, indicating its role in influencing the formation of the policy. More recently, it was uncovered that the Home Office Extremism Analysis Unit - the body created to monitor extremism following the introduction of the Prevent Duty Guidance (2015) - was receiving data directly from the Henry Jackson Society in its efforts to identify extremists (Butt v Secretary of State for Home Department 2017). This demonstrates the extent to which non-accountable neo-conservative agencies have not only influenced the direction of the Prevent policy but also tangibly shaped its practical implementation. The range of oblique activities and practices undertaken by non-governmental actors acting outwith democratic protocols and procedures generates palpable concerns with regards to responsibility, scrutiny and accountability. The predominant focus of ideational activities in the public sphere for right-wing think tanks has been oriented towards expanding the nebulous concept of extremism and indexing it to Islam and Muslims. Such disingenuous activities have fuelled Islamophobic discourses and acted as a lever to lobby government to move 'security' policy in increasingly authoritarian directions. At the same time, Muslim public figures and legitimate civil society organisations have been targeted by deliberate smears, further 
restricting and discouraging Muslim political participation in public life. This, coupled with the official counter-terrorism apparatus - an already powerful and largely unaccountable set of institutions - targeting individuals considered as extremists and those apparently radicalised has had serious repercussions. Concepts such as extremism and radicalisation are imprecisely defined in official discourse, generating widespread uncertainty at the level of identification and intervention. The flexible fashion in which these concepts are operationalised in the state bureaucracy, together with the routine practices of the police and other public servants, means that many thousands of people in the UK are now regarded as legitimate targets for suspicion, surveillance and intelligence-gathering. To this end, there is already a wide and deep body of evidence indicating that UK counter-terrorism policy has disproportionately affected and discriminated against Muslims (Qurashi 2018; Massoumi et al.2017; Kundnani 2015). Nested within Prevent - and designed to combat radicalisation - 'Channel' serves as but one example of this. Channel is the UK government's pre-criminal 'diversionary' programme, which 'provide[s] support for people vulnerable to being drawn into any form of terrorism' (HM Government 2015b). Figures released under the Freedom of Information Act and now routinely published by the Home Office - show that there has been a sharp increase in Channel referrals since the introduction of the CounterTerrorism and Security Act and the Prevent Duty Guidance in 2015. Between July 2015 and June 2016 there were 4,611 referrals - a 75 per cent increase on the previous year. Notably, of these cases some 2,311 were children under the age of 18 (including 352 under nine years old) (Massoumi et al. 2017: 11). Subsequently, the figures have continued at a similar rate, meaning that on average 12 people a day are being referred to the programme. While the revised Prevent strategy purports to deal with all forms of terrorism, the large majority of referrals to Channel relate to suspicions of Islamist extremism: 65 per cent in 2015/16 and 61 per cent in 2016/17. Alarmingly, from 2014 to 2016, young Muslims were 44 times more likely to be referred to the Channel programme than individuals of other religions (Blakeley et al. 2019). Although there was an increase in referrals and Channel support decisions for right-wing extremism in 2017/18 (Islamist extremism referrals reported at 50 per cent, compared to 32 per cent for rightwing extremism, with Channel supporting 45 per cent of decisions for Islamist extremism and 44 per cent for right-wing extremism), the Prevent programme still disproportionately targets Muslims. Yet, despite apparent rising awareness of the threat presented by individuals and groups motivated by racism and Islamophobia, none of the RICU covert activity described above was directed towards the problem of right-wing extremism. Moreover, groups racialised as White are not universally implicated in right-wing extremism, in the way that Muslim groups have had their cultural beliefs and practices spuriously used as potential indicators for extremism or radicalisation. As empirical studies have illustrated, the implementation of undemocratic counter-terrorism measures has created widespread anxiety and uncertainty for young British Muslims, who have been subjected to disproportionate forms of policing, harassment and surveillance (Khan and Mythen 
2018; Qurashi 2018; Kundnani 2009; Mythen et al. 2009). Examples of how this has transpired in practice are abundant. Section 44 of the Terrorism Act 2000 enabled the police to stop and search any person or vehicle without any requirement for 'reasonable suspicion'. Asians and Blacks were disproportionately targeted compared with Whites, with Asians being over six times more likely to be stopped and searched, and Black people on average almost eight times more likely (Massoumi et al. 2017: 8). In January 2010, Section 44 was declared unlawful by the European Court of Human Rights, in the case of Gillan and Quinton v UK. The court noted in its judgement that 'none of the many thousands of searches has ever resulted in conviction of a terrorism offence' (Gillan and Quinton v UK, 2010: para. 148). Further, Schedule 7 of the Terrorism Act 2000 sanctions draconian powers which apply to port and airport border controls allowing the detainment of individuals for up to nine hours to conduct searches of their person, allowing belongings to be seized for up to seven days. Those detained under Schedule 7 have fewer legal rights than criminal suspects: they are not entitled to a publicly-funded lawyer, are obliged to answer questions and, if detained at a police station, to provide biometric data, including fingerprints and DNA - all without a requirement of 'reasonable suspicion' (Massoumi et al. 2017: 9). While the religion of those detained under Schedule 7 is not recorded in official statistics, publicly available figures on the ethnicity of those examined or detained indicate that individuals of Pakistani ethnicity are over 150 times more likely to be detained under Schedule 7 than White British citizens (Massoumi et al.2017: 10). As flagged earlier, forms of state control and para-statal involvement in ideational projects of regulation and division underscore the ways in which uncertainty connects to issues of governance and accountability, and also index to the operation of power and the enactment of political priorities.

All of this suggests that, when we think about concrete examples where uncertainty seems rife, it is worth asking whether the issues in front of us can be viewed through a different lens and/or interpreted in a different way. Uncertainty is often associated with unknowns and futurity, but this often obscures tangible and observable phenomena. For example, how might our understanding of a given situation change if we were not to use the optic of uncertainty and risk, but instead to use that of harm and injustice? As the long-standing discrimination faced by British Muslims in the UK illustrates, history, dominant ideologies and institutionalised prejudice matter. To this end, it is vital to stress that, while the state may formally aver that it is the guardian of 'public' security, in practice the role of state intelligence and surveillance agencies in producing insecurity for certain individuals and groups is evident.

\section{Survivors of structural violence: emotion, trust and the politics of accountability}

Historical and temporal factors are also present when thinking about the consequences of political and religiously motivated violence, as Will McGowan shows in this final part of the chapter. His research focuses on the different treatment - both legal 
and cultural - received by those living in the aftermath of such violence. In this regard, the shooting of innocent protestors by the British Army in 1972 in Ireland on 'Bloody Sunday' and the coordinated bombing of London's transport system in the 2005 ' $7 / 7$ ' attacks offer contrasting points of reference. In making sense of these various pasts in the present, the two respective 'survivor groups' have had both to negotiate and traverse life since these tragic events, but in quite different ways. While the $7 / 7$ attacks were subject to close scrutiny by the state - including profiling of the perpetrators, transparent and widely publicised inquests and post-event analysis for the emergency and security services - the survivors of Bloody Sunday have spent more than four decades seeking justice through successive inquiries. Indeed, it was not until 2010 that an official apology was received from the British prime minister and, more recently, a case for prosecution belatedly brought against one of the British soldiers involved in the incident. The information made available to the public following $7 / 7$ provided at least a satisfactory 'completeness' of knowledge about how their loved ones were killed and the contextual factors surrounding the event. No such completeness was available to Bloody Sunday survivors. Within the Catholic community of Derry, it was not uncertainty that beset efforts to expose the abuses and persecution they faced, or to establish what took place at that Civil Rights march. Instead, their ability to make public those harms and to ensure an accurate and just recording of them has meant that survivors and campaigners have had perpetually to look back on events retrospectively, with little chance of 'moving on' with life as before.

Locating uncertainty within these two examples becomes very much a 'tale of two tragedies': with one in which knowledge enables at least the potential for prospective and future recovery, and the other in which the cultural and legal precedent of remembering history displaces any such hopes for transcending its impacts within living memory. Contemporary political conditions have also intermingled with these survivors' sense of collective identity and ontological security differentially, with uncertainty, fears and hypothetical resolutions relating to Brexit and the Irish border looming ever larger. The relationship between politics, emotion, (non)knowledge and power in such landmark cases is thus contingent upon the state's arbitration of them. Hannah Arendt's (1958: 237) oft-cited analysis of political promises usefully illuminates this relationship further:

The remedy for unpredictability, for the chaotic uncertainty of the future, is contained in the faculty to make and keep promises ... binding oneself through promises, serves to set up in the ocean of uncertainty, which the future is by definition, islands of security without which not even continuity, let alone durability of any kind, would be possible in the relationships between men [sic].

In the immediate aftermath of catastrophe or injustice, such events again raise pressing questions about accountability and democracy, partly because of the 
relationship Arendt highlights between those in positions of power and the demos to whom they make promises. When these promises are broken - as they are with alarming frequency - trust is not only eroded: it is difficult to win back. However, looking beyond specific actions and reactions concerning individuals, Arendt's analysis of uncertainty merits closer attention in relation to the relationship between governance, emotion and trust. Unlike Arendt's remedy for unpredictability, which provides islands of security, today's political landscape presents us with insecurity as an unceasing and inevitable feature of social, economic and political life. Catastrophe, vulnerability and surprise perpetually await us and must be embraced; preparation to deal with the jolts and shocks generated by twentyfirst century turbo-capitalism must be prioritised, and represent something of an emotional retraining exercise. As Mark Neocleous (2012: 188) posits, the nature of today's security politics might be epitomised in the maxim: 'don't be scared, be prepared'. The actual emotions engendered under such political conditions - the preponderance of which are likely to be negative ones, such as fear and anger - may encourage an inward-turning and acquiescent citizenry. Whether or not this is the case, they provide no basis for long-term stability, or happiness.

\section{Four concluding provocations}

In drawing the chapter to a close, it has been our intention to deploy concrete examples of the ways in which problems of uncertainty have an impact upon 'security' in its many guises, from policy and practice to the ontological and emotional. Having discussed several problematiques that arise when we seek to engage in debates about uncertainty in the context of security, we wish to end by offering up four caveats that serve as simultaneous provocations. First, it is our contention that, rather than analysing uncertainty as a purely abstract concept, we need to situate it in specific contexts of knowledge and grounded cultural milieu. The dangers of presentism - through which histories of uncertainty might become masked - are obvious in this regard. Second, having identified a set of specific practices to focus on, it is important to remain alert to the different characteristics of uncertainty, and to speak consistently about particular strands across a chosen set of observations. Third, as we have demonstrated, it is important to be aware of - and alert to - the pursuit of narrow, sectoral interests that may lurk beneath the veil that uncertainty enables. Fourth, and relatedly, we would counsel against 'uncertainty imperialism', whereby the term becomes used as a catch-all lingua franca that is devoid of specificity. Mirroring academic overuse of 'risk' as an heuristic device, if we are loose in bandying about the discourse of 'uncertainty' there is a palpable danger of catachresis. While theoretically exploring the constitution of uncertainty adds to the corpus of academic knowledge, as we have intimated, overstretching its explanatory potential may serve to shroud rather than elucidate more pressing and critical analyses of power relations, inequalities and injustices. 


\section{References}

Anan, M. (2019) Cost of No Deal Revisited. UK in a Changing Europe, https://ukandeu.ac.uk/ wp-content/uploads/2018/09/Cost-of-No-Deal-Revisted.pdf (15 September 2019)

Arendt, H. (1958) The Human Condition, Chicago: University of Chicago Press

Ashford, W. (2019) 'UK Committed to Working with EU Cyber Security Partners', ComputerWeekly.com, 21 February 2019, www.computerweekly.com/news/252458102/ UK-committed-to-working-with-EU-cyber-security-partners (accessed 13 September 2019)

Blakeley, R., Hayes, B., Kapoor, N., Kundnani, A., Massoumi, N., Miller, D., Mills, T., Sian, K. and Tufail, W. (2019) Leaving the War on Terror, London: Transnational Institute

Butt v Secretary of State for the Home Department [2017] EWHC 1930 (Admin)

Carrapico, H. and Barrinha, A. (2017) 'The EU as a Coherent (Cyber)Security Actor?', Journal of Common Market Studies 55.6: 1254-1272

Carrapico, H., Niehuss, A. and Berthelemy, C. (2019) Brexit and Internal Security - Political and Legal Concerns in the context of the Future UK-EU Relationship, Basingstoke: Palgrave

Cobain, I., Ross, A., Evans, R. and Mahmood, M. (2016) 'Inside Ricu, the Shadowy Propaganda Unit Inspired by the Cold War', The Guardian, 2 May 2016, www.theguardian. com/politics/2016/may/02/inside-ricu-the-shadowy-propaganda-unit-inspired-bythe-cold-war (accessed 23 October 2019)

DCLG (2007) Preventing Violent Extremism: Winning Hearts and Minds, London: HMSO

Dodd, V. (2009) 'Government Anti-terrorism Strategy "Spies on Innocent”, The Guardian, 16 October 2009, www.theguardian.com/uk/2009/oct/16/anti-terrorism-strategyspies-innocents (accessed 12 February 2020)

European Commission (2019) Europeans' Attitudes Towards Internet Security, Special Eurobarometer 480DG for Migration and Home Affairs and DG for Communication, March edition, Brussels

- (2018) Speech by Vice-President Ansip at the Cyber Security Conference in Vienna, 3 December. Vienna, https://ec.europa.eu/commission/commissioners/2014-2019/ ansip/announcements/speech-vice-president-ansip-cyber-security-conference-vienna_ en (accessed 10 September 2019)

(2017) Joint Communication to the European Parliament and the Council: Resilience, Deterrence and Defence: building strong cybersecurity for the EU,JOIN(2017)450 final, Brussels (13 September 2017). https://ec.europa.eu/transparency/regdoc/rep/10101/ 2017/EN/JOIN-2017-450-F1-EN-MAIN-PART-1.PDF (accessed 10 September 2019)

European Commission and HREU (2013) Joint Communication to the European Parliament, The Council, The European Economic and Social Committee and the Committee of the Regions: Cybersecurity Strategy of the European Union: An Open, Safe and Secure Cyberspace, JOIN(2013)1 final

Gillan and Quinton v UK (2010) European Court of Human Rights Transcript, 12 January

Harcup, A. (2019) 'Brexit Uncertainty and Resulting Cybersecurity Concerns', SC Media, July 2019, www.scmagazineuk.com/brexit-uncertainty-resulting-cybersecurityconcerns/article/1588883 (accessed 16 September 2019)

HM Government (2015a) Revised Prevent Duty Guidance: For England and Wales, London: The Stationary Office Limited, https://assets.publishing.service.gov.uk/government/ uploads/system/uploads/attachment_data/file/445977/3799_Revised_Prevent_Duty_ Guidance_England_Wales_V2-Interactive.pdf (accessed 23 October 2019)

- (2015b) Channel Duty Guidance, London: The Stationary Office Limited, www.gov. uk/government/publications/channel-guidance (accessed 17 August 2018)

— (2011) Prevent Strategy, London: The Stationary Office Limited, www.gov.uk/government/publications/prevent-strategy-2011 (accessed 2 May 2018) 
Hooper, S. (2017) 'Google-Hosted Muslim Leaders Summit Linked to Home Office Prevent Unit', Middle East Eye, 11 January 2017, www.middleeasteye.net/news/google-hostedmuslim-leaders-summit-linked-home-office-prevent-unit (accessed 23 October 2019)

Intelligence and Security Committee (2012) Annual Report 2011-2012, https://assets. publishing.service.gov.uk/government/uploads/system/uploads/attachment_data/file/ 211559/ISC-2011-12.pdf (accessed 27 September 2019)

Khan, F. and Mythen, G. (2018) 'Micro Level Management of Islamophobia', in I. Awan and I. Zempi (eds) The Routledge International Handbook of Islamophobia, London: Routledge

Kundnani,A. (2015) A Decade Lost: Rethinking Radicalisation and Extremism, London: Claystone - (2009) Spooked! How Not to Prevent Violent Extremism, London: Institute of Race Relations

Massoumi, N. and Miller, D. (2019) Counter Terrorism and Muslim Civil Society, London: Spinwatch

Massoumi N., Mills T. and Miller, D. (2019) 'Secrecy, Coercion and Deception in Research on "Terrorism" and "Extremism", Contemporary Social Science, DOI: 10.1080/ 21582041.2019.1616107

Massoumi, N., Mills, T. and Miller, D. (2017) What is Islamophobia? Racism, Social Movements and the State, London: Pluto Press

McGowan, W. (2018) 'The Perils of "Uncertainty" for Fear of Crime Research in the 21st Century', in M. Lee and G. Mythen (eds) The International Handbook on Fear of Crime, London: Routledge

Miller, D. and Massoumi, N. (2016) Briefing on the Home Office, RICU and Muslim Civil Society Groups. Submission to the Home Affairs Select Committee Countering Extremism Inquiry, CEX0062, 10 June

Miller, D., Massoumi, N. and Mills, T. (2017) 'The Challenge of Islamophobia', in M.Wakefield (ed) Why We Need A New Foreign Policy: A Stop the War Coalition Briefing, London: Stop the War Coalition

Mills, T., Griffin, T. and Miller, D. (2011) The Cold War on British Muslims: An Examination of Policy Exchange and the Centre for Social Cohesion, Glasgow: Public Interest Investigations

Mythen, G., Walklate, S. and Khan, F. (2009) "'I'm a Muslim, but I'm not a Terrorist": Risk, Victimization and the Negotiation of Risky Identities', British Journal of Criminology 49.6: 736-754

Mythen, G., Walklate, S. and Peatfield, E.J. (2017). 'Assembling and Deconstructing Radicalisation in PREVENT: A Critique of the Logic of Drivers', Critical Social Policy 37.2: 180-201

National Risk Register of Civil Emergencies (2017) London: Cabinet Office

Neocleous, M. (2012) “'Don't Be Scared, Be Prepared”: Trauma-Anxiety-Resilience', Alternatives: Global, Local, Political 37.3: 188-198

O’Toole, T., DeHanas, D.N., Modood, T., Meer, N. and Jones, S. (2013) Taking Part: Muslim Participation in Contemporary Governance, Bristol: University of Bristol

Qurashi, F. (2018) 'The Prevent Strategy and the UK "War on Terror": Embedding Infrastructures of Surveillance in Muslim Communities', Palgrave Communications 4.17: $1-13$

Scoones, I. (2019) What is Uncertainty and Why Does it Matter?, STEPS Working Paper 105, Sussex: STEPS Centre

Stevens, T. and O’Brien, K. (2019) 'Brexit and Cyber Security', RUSI Journal 164.3: 22-33

UK National Cyber Security Centre (2019) 'Ciaran Martin's Speech at the Billington Cyber Security Summit', 6 September, Washington DC, www.ncsc.gov.uk/speech/ciaranmartins-speech-at-billington-cyber-security-summit-2019 (accessed 14 September 2019) 